International Journal of Engineering \& Technology, 9(1)(2020)211-217
International Journal of Engineering \& Technology
SPC
Website: www.sciencepubco.com/index.php/IJET
Research paper

\title{
Comparing continuous control policies by modeling and simulation of the procurement process
}

\author{
Abdessamad Douraid ${ }^{1}$ *, Hamid Ech-Cheikh ${ }^{1}$, Khalid El Had ${ }^{1}$, Mohamed Laradi ${ }^{2}$ \\ ${ }^{1}$ Institut Supérieur d'Etudes Maritimes, Casablanca, Morocco \\ ${ }^{2}$ Faculty of engineering and computing Priory Street Coventry CVI 5FB Coventry University (UK) \\ *Corresponding author E-mail: abdessamad.douraid@gmail.com
}

\begin{abstract}
Inventory management is a challenging problem area in supply chain management and companies need to have inventories in warehouses in order to satisfy customer's needs. Meanwhile, these inventories have holding costs and this is a frozen fund that can be lost. Therefore, the task of inventory management is to find the right quantity of inventories that will fulfill the demand with the right price, avoiding overstocks. The aim of this paper is to carry out a comparing study of continuous inventory control policies in a stochastic environment of demand and lead time, in order to find out the impacts of the decision variables of each inventory control policy. For this purpose, the discrete event simulation approach has been chosen to generate various scenarios of inventory control policies of the procurement process by taking into account the production planning of the manufacturing company. The comparison of these configurations based on the essential key performance indicators of the supply chain, namely the cost and service level.
\end{abstract}

Keywords: Comparing Study; Supply Chain; Continuous Control; Discrete Event Simulation.

\section{Introduction}

Nowadays, the management of supply chain flows is becoming a fundamental activity for competitiveness. In fact, globalization is changing the way in which companies arrange their procurement, production and distribution activities. Keeping continuity to the progression of effectiveness and the increasing competitive level, one may say that today there is no existence of competition among companies, simply, but competition among the whole supply chain. This again leads to the conclusion that good supply chain management will define who will stay and who will leave the market [1]. Moreover, manufacturing industries are suffering from an increasing requirement for more flexibility and agility to deal with the uncertainty of demand, also obvious at the interfaces connecting suppliers and manufacturers along the supply chain.

In the literature, there are some proposals of unified policies, but the analytical results are still rather slight. We are among the first to characterize and simulate the performance of an inventory policy that takes into account both quantity to order and time to order restrictions at the same time. In most of the inventory literature, it is assumed that a periodic review policy accounts for backorder cost only through the total backordering level at the end of a fixed accounting period [2].

This research focuses on the simulation of continuous and periodic review of the procurement process taking into account the production planning of a manufacturing company, where customer demand and lead time are stochastic. The benchmark of these configurations is based on the following key performance indicators: inventory levels, costs, and service levels.

The paper is organized as follows: Section II is concerned with literature review on the supply chain management system, inventory control policies and simulation to identify the existing gaps of literature. Section III presents the research methodology and description of the case study. Section IV discussing the essential part of our research which is the simulation of various inventory review policies of the system. Finally, the results of scenarios and highlights on of future research are discussed in section V and VI.

\section{Inventory control management and simulation}

Supply Chain Management is a network of facilities that produce raw materials, transform them into intermediate goods and then final products, and deliver the products to customers through a distribution system. It spans procurement, manufacturing, and distribution, [3] the main purpose of supply chain management is to optimize performance of the chain to add as much value as possible for the least cost possible. In other words, it targets to relate all the supply chain contributors to jointly cooperate within the enterprise as a way to maximize productivity in the supply chain and deliver the most benefits to all related parties [4]. Adoption of Supply chain management practices in industries has steadily increased since the 1980s. A number of definitions are proposed and the concept is discussed from many perspectives. However, [5], [6] and [7] provided an excellent review of supply chain management literature. These papers define the concept, 
principals, nature, and development of SCM and indicate that there are intense researches being conducted around the world in this field they critically assessed developments in the theory and the practice of supply management.

Supply chain management consists of several sectors, one of which is inventory management, which is part of the internal company's job. If the company can manage inventory system effectively and efficiently, thus it could make a result in a reduction of operating costs [8]. Inventory system refers to the solving problems of stock in the business. Good stock management will maximize business benefits, and vice versa, the failure to control the stock will result in a loss benefit of the company [9].

Generally, there are two replenishment policies are often used in practice, those are continuous review and periodic review. The continuous review indicates that inventory status continues to be tracked and ordering according to lot size (Q) was done when the level is reached entrusted inventory reorder point (ROP). While periodic review indicates that inventory status tracked at regular periodic intervals and reorder was made to raise the inventory level to the point of a predefined. These inventory system policies are not comprehensive, but sufficiently to provide solutions to problems concerning the safety of the inventory management system [8].

The advantage of continuous review is to address the situation where demand is high but the disadvantage is variable order quantity. The supplier can make mistakes more often and they would prefer the customers who ordered the fixed order quantity. This situation is vice versa with periodic review policy [10]. Here there are inventory profiles [11]:

Continuous Review (Q method)

$\mathrm{SS}=\mathrm{FS}-1(\mathrm{CSL}) \mathrm{x} \sigma \mathrm{L}$

$\mathrm{ROP}=\mathrm{DL}+\mathrm{SS}$

$\mathrm{CI}=\mathrm{Q} / 2$

$\mathrm{AIL}=\mathrm{CI}+\mathrm{SS}$

$\mathrm{DL}=\mathrm{DL}$

$\sigma \mathrm{L}=\sqrt{ } \mathrm{L} \sigma \mathrm{D}$

$\mathrm{Q}=\sqrt{ }(2 \mathrm{DeS}) / \mathrm{hC}$

Periodic Review (P method)

$\mathrm{SS}=\mathrm{Fs}-1(\mathrm{CSL}) \mathrm{x} \sigma \mathrm{T}+\mathrm{L}$

$\mathrm{DT}+\mathrm{L}=(\mathrm{T}+\mathrm{L}) \mathrm{D}$

$\sigma \mathrm{T}+\mathrm{L}=\sqrt{ }(\mathrm{T}+\mathrm{L}) \sigma \mathrm{D}$

$\mathrm{OUL}=\mathrm{DT}+\mathrm{L}+\mathrm{SS}$

$\mathrm{AIL}=(\mathrm{DT}) / 2+\mathrm{SS}$

With:

$\mathrm{SS}=$ safety stock

$\mathrm{CSL}=$ cycle service level

$\mathrm{CI}=$ cycle inventory

$\mathrm{ROP}=$ reorder point

Supply Chain Management is a network of facilities that produce raw materials, transform them into intermediate goods and then final products, and deliver the products to customers through a distribution system. It spans procurement, manufacturing, and distribution, [3] the main purpose of supply chain management is to optimize performance of the chain to add as much value as possible for the least cost possible. In other words, it targets to relate all the supply chain contributors to jointly cooperate within the enterprise as a way to maximize productivity in the supply chain and deliver the most benefits to all related parties [4]. Adoption of Supply chain management practices in industries has steadily increased since the 1980s. A number of definitions are proposed and the concept is discussed from many perspectives. However, [5], [6] and [7] provided an excellent review of supply chain management literature. These papers define the concept, principals, nature, and development of SCM and indicate that there are intense researches being conducted around the world in this field they critically assessed developments in the theory and the practice of supply management.

Supply chain management consists of several sectors, one of which is inventory management, which is part of the internal company's job. If the company can manage inventory system effectively and efficiently, thus it could make a result in a reduction of operating costs [8]. Inventory system refers to the solving problems of stock in the business. Good stock management will maximize business benefits, and vice versa, the failure to control the stock will result in a loss benefit of the company [9].

Generally, there are two replenishment policies are often used in practice, those are continuous review and periodic review. The continuous review indicates that inventory status continues to be tracked and ordering according to lot size (Q) was done when the level is reached entrusted inventory reorder point (ROP). While periodic review indicates that inventory status tracked at regular periodic intervals and reorder was made to raise the inventory level to the point of a predefined. These inventory system policies are not comprehensive, but sufficiently to provide solutions to problems concerning the safety of the inventory management system [8].

The advantage of continuous review is to address the situation where demand is high but the disadvantage is variable order quantity. The supplier can make mistakes more often and they would prefer the customers who ordered the fixed order quantity. This situation is vice versa with periodic review policy [10]. Here there are inventory profiles [11]:

Continuous Review (Q method) 
$\mathrm{ROP}=\mathrm{DL}+\mathrm{SS}$

$\mathrm{CI}=\mathrm{Q} / 2$

$\mathrm{AIL}=\mathrm{CI}+\mathrm{SS}$

$\mathrm{DL}=\mathrm{DL}$

$\sigma \mathrm{L}=\sqrt{ } \mathrm{L} \sigma \mathrm{D}$

$\mathrm{Q}=\sqrt{ }(2 \mathrm{DeS}) / \mathrm{hC}$

Periodic Review (P method)

$\mathrm{SS}=\mathrm{Fs}-1(\mathrm{CSL}) \times \sigma \mathrm{T}+\mathrm{L}$

$\mathrm{DT}+\mathrm{L}=(\mathrm{T}+\mathrm{L}) \mathrm{D}$

$\sigma \mathrm{T}+\mathrm{L}=\sqrt{ }(\mathrm{T}+\mathrm{L}) \sigma \mathrm{D}$

$\mathrm{OUL}=\mathrm{DT}+\mathrm{L}+\mathrm{SS}$

$\mathrm{AIL}=(\mathrm{DT}) / 2+\mathrm{SS}$

With:

$\mathrm{SS}=$ safety stock

$\mathrm{CSL}=$ cycle service level

$\mathrm{CI}=$ cycle inventory

$\mathrm{ROP}=$ reorder point

\section{Research methodology and case study description}

Based on the literature review that we have carried out on supply and production systems, we were able to identify all the elements to incorporate into our model. Indeed, we have taken as a case study analysis of the electronics' industry supply system. In fact, this sector is characterized by a set of aspects that are obviously very numerous and interdependent, which makes the study of such case much more complex.

In this case study, each finished product is made of several components. We assume that the demand for the finished product and the lead times are stochastic. Therefore, we face several problems in this study as the difficulty of controlling the different flows, the variability of demand and the compromise time-cost-quality.

The configuration of the simulation model is as follows:

- Simulation: three-month horizon;

- Supply System: 1 material component;

- Production line: 7 finished products;

- The number of suppliers: 3 suppliers.

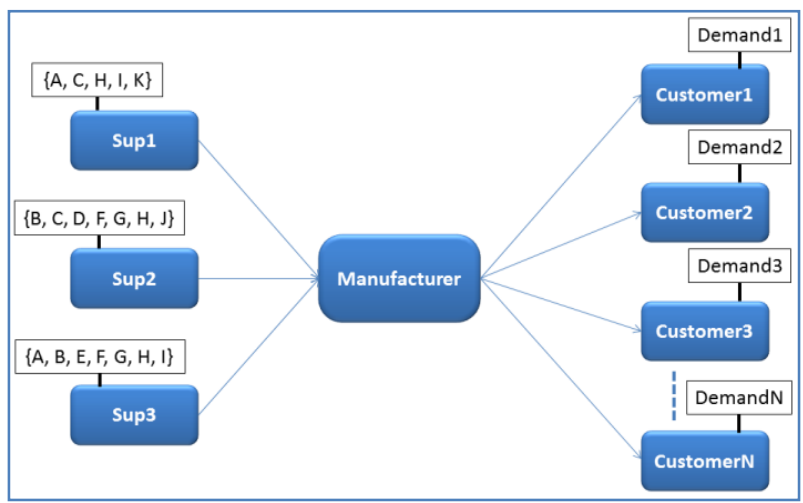

Fig. 1: Case Study Structure.

Absolutely, the control of procurement process becomes much more difficult due to the interdependence of flow components in the number of finished products (Bill of Material) and variability in demand for each product.

Simulation plan: we performed the simulation of each scenario with a three-month horizon. Simulation campaigns are sufficiently numerous and long term to overcome the transitional phase of the system and take into account of random phenomena. We simulated all these scenarios in a stochastic environment of demand and delivery times.

Table 1: Sample of the Normal Distribution of Data for the Simulation of Scénario_01

\begin{tabular}{lll}
\hline & Distribution & Unit \\
\hline Normal demand arrival & Norm $(160 ; 17)$ & Product/Day \\
Urgent demand arrival & Norm $(15 ; 3)$ & Product/Day \\
\hline
\end{tabular}


The scenarios studied concerns the simulation of the impact of continuous reviews (r, Q) and (s, S) policies on the system.

Simulator system (inputs/outputs):

In this section, we present all the simulated scenarios. We focused on the performance of different configurations in terms of stock levels of components (raw material) and finished products, different total costs (procurement cost, holding cost and backorder cost), and service level as well.

Firstly, we present the results of the reference scenario for each type of procurement policy. We will then analyze the results for all the simulated scenarios to compare and interpret according to the decision variables integrated into our system (Figure 2).

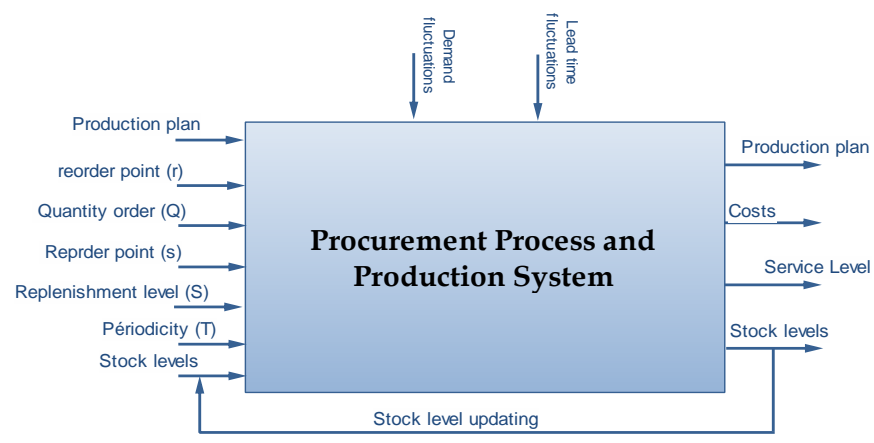

Fig. 2: System Characterization

The data moving dynamically while the simulation running in the Arena@ software. The majority of the values are found only in the Arena $\odot$ simulation itself. However, the use of external databases to simulation allows several advantages. You can change the initial parameters of the simulation more quickly, keep track of transactions in the simulation and display the desired results more easily.

Nevertheless, for complex systems, it is better to create sub-models and use the special blocks "Station" and "Route" for transferring entities. The entities included in the sub-model by a block and then leave the "Station" by a "route" block that ensures the transfer of entities to the determined destination. Therefore, the main simulation sub-models have shown in figure 3.

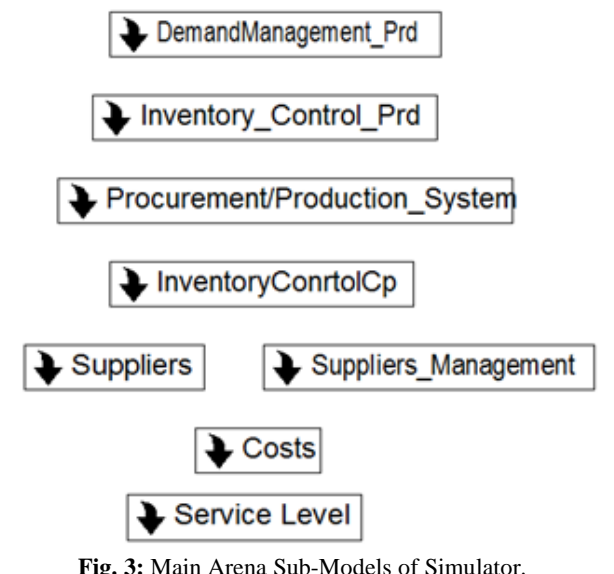

Before running the simulation, we should check if there are errors in the simulator. So if no error is detected, the software creates the SIMAN code corresponding to the model developed. Once the checking is done and SIMAN code generated, the simulation model shown in Figure 3 is executed.

\section{Results and discussion}

\subsection{Continuous control policy $(r, Q)$}

a) Reference Scenario (Scenario_01) for (r, Q) policy

The system is simulated under the initial conditions quantities of stock in components and finished products, etc. The results obtained by the simulation of scénario_01 in these initial conditions will be used as a reference for comparing system performance to other scenarios. The results of the reference simulation are shown in figure 4. These results show that the service level is good enough since it stabilizes around approximately $80 \%$. However, this scenario generates significant inventory components, which involve extra costs of holding, procurement, and production. Figure 4_A respectively present the most consumed and less consumed product (Prd5 and Prd1), and Figure 4_B concerns the evolution of stock of the most consumed component (StockD), and the least consumed (StockA). 


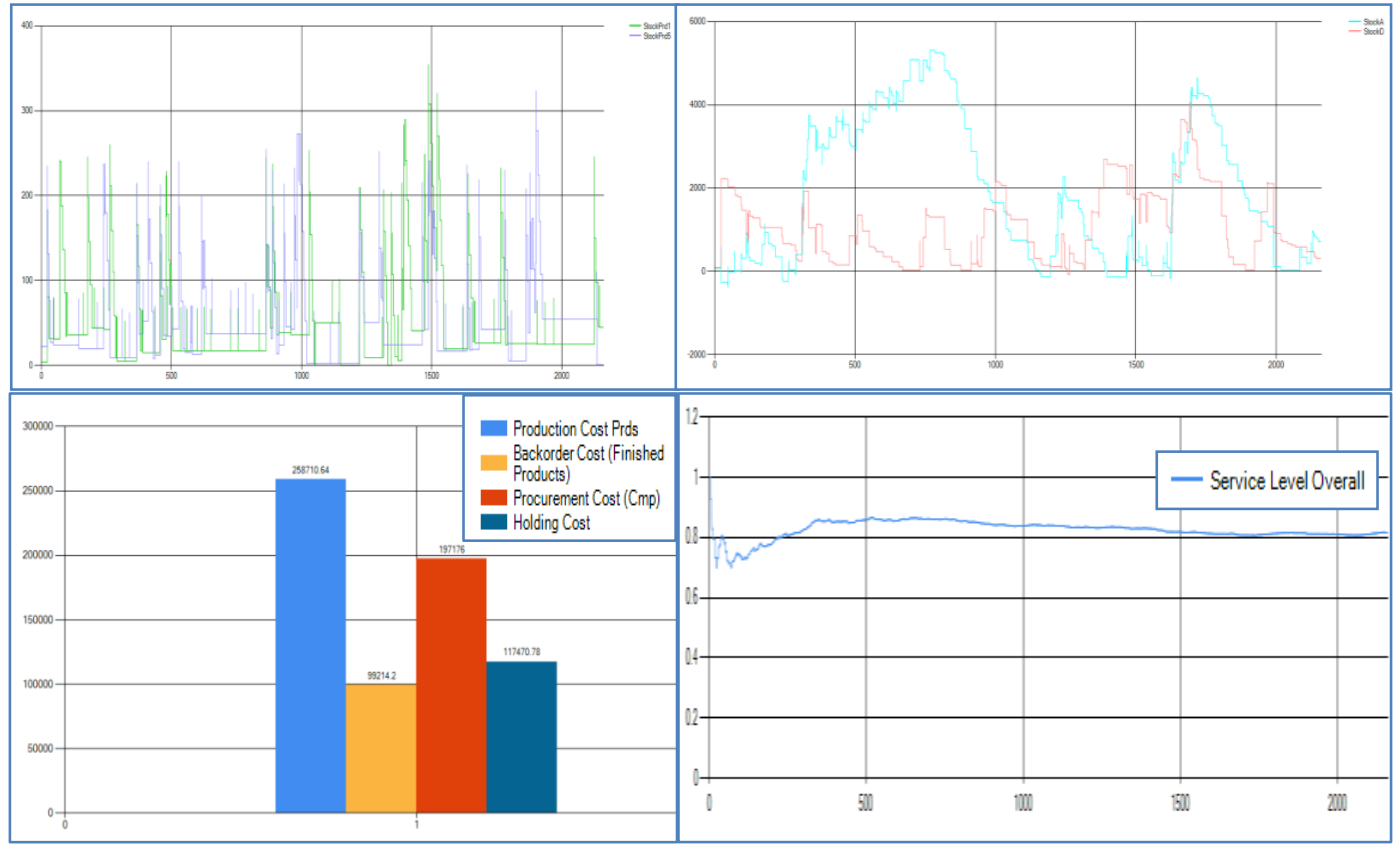

Fig. 1: System Performance (Scenario_01).

In the following results, we will vary the order quantity " $Q$ " and the reorder point " $r$ " of $+/-20 \%$, in order to determine the impact of the decision variables on the system and compare different scenarios of the continuous review policy (r, Q). However, since changes in stock levels are proportional to the costs, we will reduce the demonstration of the results by representing only the costs and the overall level of service.

b) Comparing scenarios of continuous control policy (r, Q)

Table 2: Scenarios of Continuous Control Policy (R, Q)

\begin{tabular}{lll}
\hline Scenario Nbr & Description & Figure Nbr \\
\hline Scenario_01 & Reference scenario (r, Q) policy & Figure 4 \\
Scenario_02 & Variation by increasing the order quantity Q & Figure 5 \\
Scenario_03 & Variation by decreasing the order quantity Q & Figure 6 \\
Scenario_04 & Variation by increasing the reorder point r & Figure 7 \\
Scenario_05 & Variation by decreasing the reorder point r & Figure 8 \\
\hline
\end{tabular}

The results of scenarios 2, 3, 4 and 5 are shown respectively in figures 5, 6, 7 and 8 below.

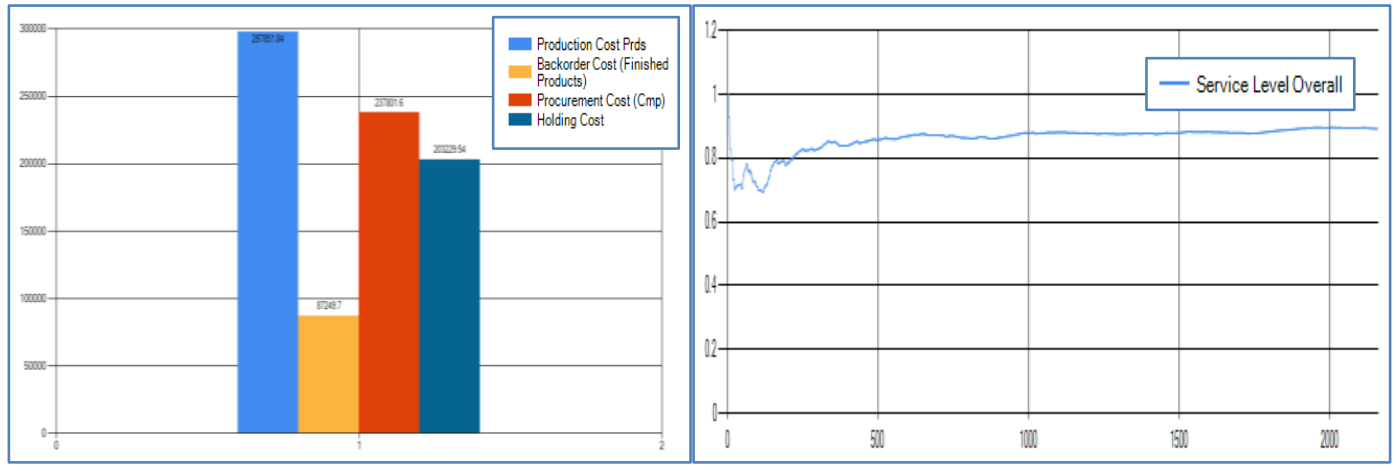

Fig. 5: System Performance (Scenario_02).

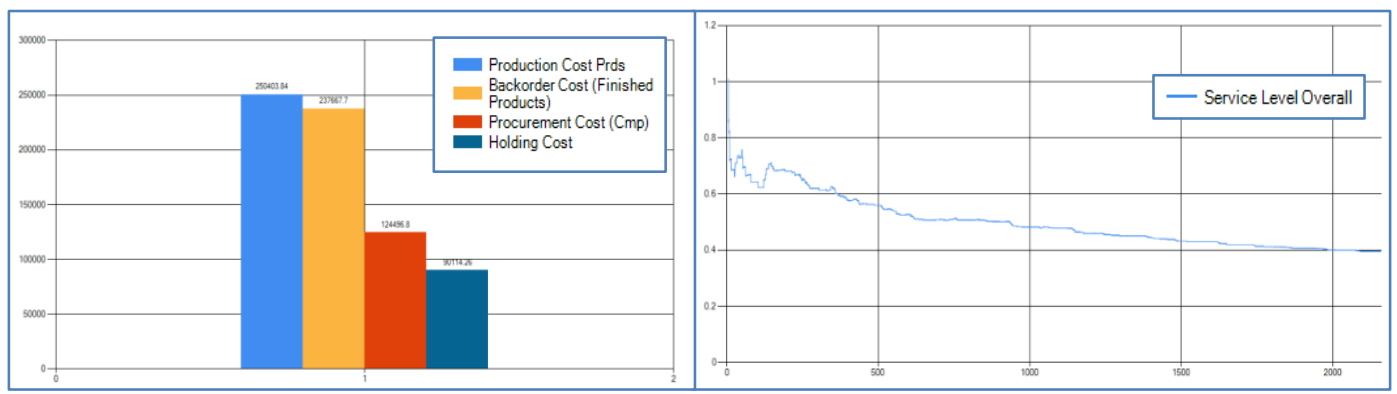

Fig. 6: System Performance (Scenario_03). 


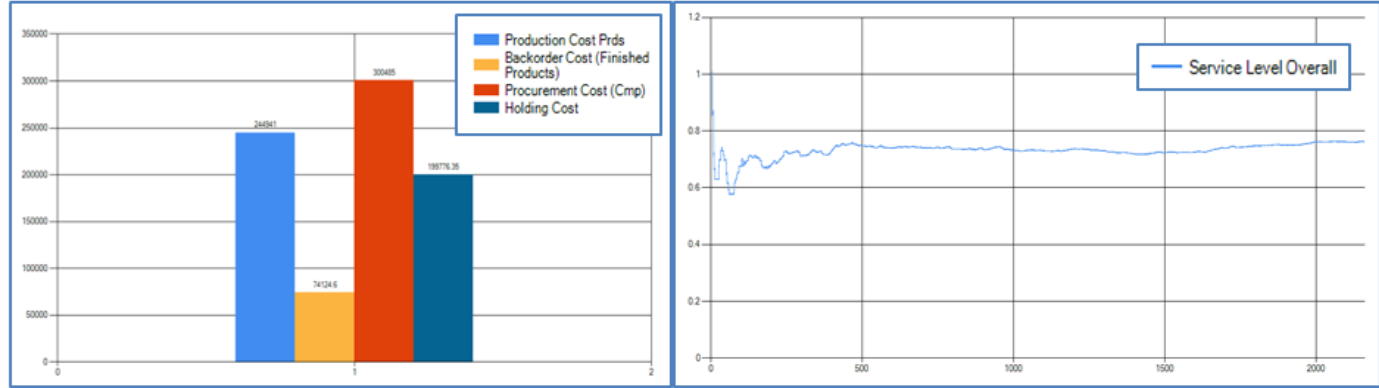

Fig. 7: System Performance (Scenario_04).

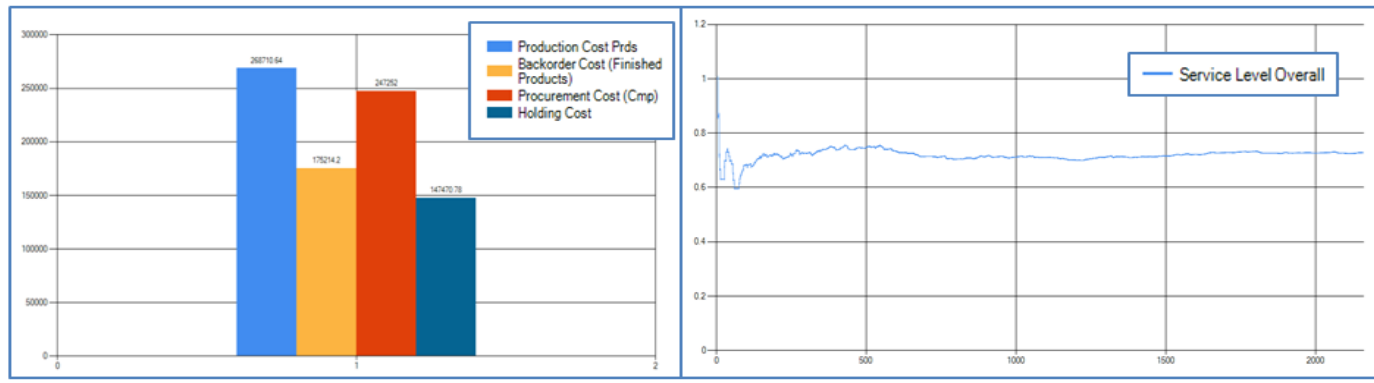

Fig. 8: System Performance (Scenario_05).

Based on the service level of each scenario (1,2,3,4 and 5) and the comparative table of total costs (Table 3 ), we note that Scenario 2 has the best service level which approaches $90 \%$. This scenario generates a total cost slightly higher than the cost of the reference configuration (scenario 1) and avoid backorders of finished products.

Table 3: Costs of Continuous Policy (R, Q) Scenarios

\begin{tabular}{|l|c|c|c|c|c|}
\cline { 2 - 6 } \multicolumn{1}{c|}{} & $\begin{array}{c}\text { Production } \\
\text { cost }\end{array}$ & $\begin{array}{c}\text { Backorder } \\
\text { cost }\end{array}$ & $\begin{array}{c}\text { Procurement } \\
\text { cost }\end{array}$ & $\begin{array}{c}\text { Holding } \\
\text { cost }\end{array}$ & $\begin{array}{c}\text { Total } \\
\text { cost }\end{array}$ \\
\hline Scenario_01 & 258710.64 & 99214.2 & 197176 & 117470.78 & 672571.62 \\
\hline Scenario_02 & 297851.84 & 87249.7 & 237801.6 & 203229.54 & 826132.68 \\
\hline Scenario_03 & 250403.84 & 237667.7 & 124496.8 & 90114.26 & 702682.6 \\
\hline Scenario_04 & 244941 & 74124.6 & 300485 & 199776.35 & 819326.95 \\
\hline Scenario_05 & 268710.64 & 175214.2 & 247252 & 147470.78 & 838647.62 \\
\hline
\end{tabular}

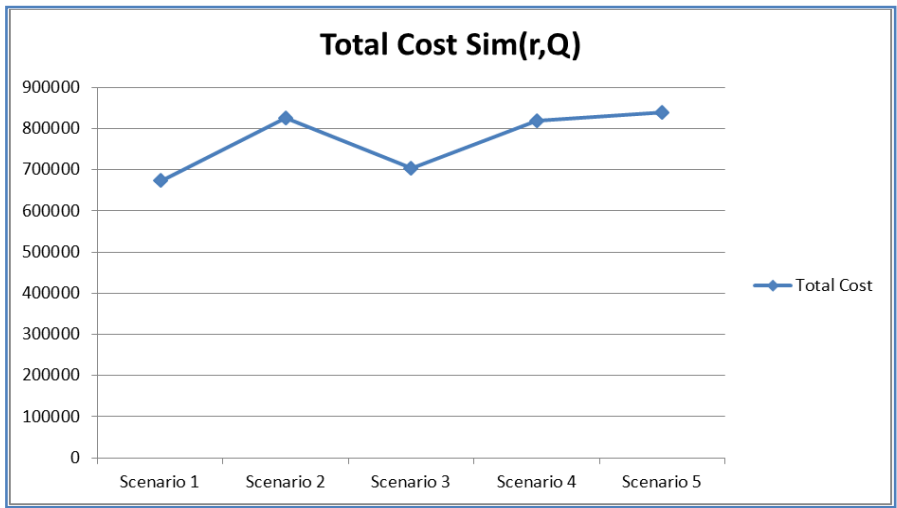

Fig. 9: Cost Comparison of Different Scenarios of (R, Q) Policy.

Therefore, we found out that the decision variable $\mathrm{Q}$ has a strong effect on the behavior of the system. On the other hand, $\mathrm{r}$ stock replenishment point does not influent too much on the system performance, except when it roses, it gives rise to more stock in raw material which involves additional holding costs possession of additional.

\section{Conclusion and outlook}

The simulation results of the obtained scenarios demonstrate the difficulty of conducting the procurement process and production planning. This difficulty depends mainly on the number of variables and characteristics that we took into consideration. This paper presents a set of simulation, the results of these simulations and analysis allowed to list substantial concepts on the dynamics of the studied system. We have listed some observations based on the case study and the parameters that we took into consideration:

- The variability of replenishment points $r$ or $s$, have not a real influence on system performance when it is under a continuous review. Otherwise, they expose the system to backorder risks when the decreases relative to their mean values, as close to the value of safety stock.

- The variability of the quantities Q and S respectively in the policies (r, Q) and (s, S), shows a noteworthy impact on the system results. These two variables present certain proportionality with the service level as well as the global cost. 
Consequently, for more development of the current simulator, we propose in future researches to insert the temporal variables in the system to make a new

\section{References}

[1] Martins, P.T.; Laugeni, F. P. Administração da produção., São Paulo, SP: Editora Saraiva, 2002.

[2] Ann Arborr, Approximation Algorithms for the Stochastic Lot-sizing Problem with Order Lead Times, 2011.

[3] Lee, HL \& Billington, C, 'The evolution of supply chain management models and practices at Hewlett Packard', Interface, Vol. 25, no.5, pp.42-63, 1995. https://doi.org/10.1287/inte.25.5.42.

[4] Finch, BJ, 'Operations Now: Profitability, Processes, Performance', 2nd edn, McGraw-Hill/ Irwin, United States, 2006.

[5] Cousins,P.D., Lawson,B., Squire,B., 2006 . Supply chain management: theory and practice - the emergence of an academic discipline. International Journal of Operations \& Production Management, 26 (7), pp.697 - 702. https://doi.org/10.1108/01443570610672194

[6] Sachan,A., Datta,S., 2005.Review of supply chain management and logistics research International Journal of Physical Distribution \& Logistics Management, 35 (9), pp. 664 - 705. https://doi.org/10.1108/09600030510632032.

[7] Storey,J., Emberson,C., Godsell,J., Harrison,A., 2006. Supply chain management: theory, practice and future challenges. International Journal of Operations \& Production Management, 26 (7), pp. 754 - 774. https://doi.org/10.1108/01443570610672220.

[8] Chopra, S.; et al. 2010. Supply Chain Management: Strategy, Planning, and Operation. New Jersey: Pearson.

[9] F. D. Hedrick et al, "Inventory Management. Purchasing for Owners of Small Plants," Buying for Retail Stores and Inventory Management, 2012.

[10] C. Laeiddee, "Improvement of Re-Order Point for Drug Inventory Management at Ramathibodi Hospital," Master Thesis, Mahidol University, 2010.

[11] Setyaningsih S., Comparison Continuous and Periodic Review Policy Inventory Management System Formula and Enteral Food Supply in Public Hospital Bandung, International Journal of Innovation, Management and Technology, Vol. 4, No. 2 , April 2013. https://doi.org/10.7763/IJIMT.2013.V4.401.

[12] Caroline Thierry, The Role of Modeling and Simulation in Supply Chain Management, SCS M\&S Magazine - Oct. 2010. 